\title{
VIEWPOINT
}

\section{Public Spaces in the Arab Region}

Elaf Raslan, Lubna Shaheen

UN-Habitat, Regional Office for Arab States

elaf.raslan@un.org | lubna.shaheen@un.org

\begin{abstract}
The Arab Region has been facing several challenges. While some countries are facing socio-economic issues, others have been civil strife and conflict. In both cases, public spaces play an important role in tackling these issues, and in cities' social, economic, health and environmental life, since they contribute to build social cohesion, improve the quality of human interactions and the physical and mental health of inhabitants. Based on this, UN-Habitat has been supporting the development of 'Public Spaces in the Arab Region' programme since 2016. The programme has been rehabilitating public spaces using participatory tools to foster sustainable development and ultimately achieve SDG II, target II.7.

However, the implementation of these siloed projects, coupled with lack of data, inadequate design and improper management didn't allow for the development of a strategic plan for public spaces in the cities of the Arab Region. Acknowledging such issues and challenges, the programme in cooperation with the UN-Habitat's Global Public Space programme is further developing the regional approach to focus on rehabilitating public spaces that are safe for the most vulnerable groups, in particular women and girls, given the violence they face in the public domain. The programme is also working with relevant stakeholders and authorities to upscale such projects and to develop a city-wide public space network that is aligned with a strategic action plan.
\end{abstract}

Keywords: Arab Region, COVID response, urbanisation, public spaces, VAWG

To cite this article:

Raslan, E., Shaheen, L. (202I) Public Spaces in the Arab Region, The Journal of Public Space, 6(I), 235-240, DOI 10.3289I/jps.v6il.I463

This article has been reviewed by the Editors and accepted for publication in The Journal of Public Space.

(c) (5) This work is licensed under a Creative Commons Attribution - Non Commercial 4.0 International License https://creativecommons.org/licenses/by-nc/4.0/ 


\section{Introduction}

'Public spaces are all places publicly owned or of public use, accessible and enjoyable by all for free and without a profit motive. Public spaces are a key element of individual and social well-being, the places of a community's collective life, expressions of the diversity of their common, natural and cultural richness and a foundation of their identity.' During the 23rd Governing Council the member states mandated UN-Habitat to address issues of public space and to include it in its overall agenda to improve the quality of life in cities and to pursue sustainable urban development. In addition, target I I.7 of the Sustainable Development Goal I I ("Making cities and human settlements inclusive, safe, resilient and sustainable") refers directly to public space: "By 2030, provide universal access to safe, inclusive and accessible, green and public spaces, particularly for women and children, elderly, and persons with disabilities." UN-Habitat's is mandated to advance the agenda on public spaces and placemaking, implement public space projects that encourage the participation of the vulnerable groups like women, youth, elderly and children and use these experiences to disseminate the further practical knowledge on public spaces and their implementation.

\section{Challenges in the Arab Region}

The Arab Region is diverse in nature; geographically divided into the Gulf countries, Mashreq countries, Maghreb and Egypt and Sudan. Though there are common issues that were highlighted since $20 \mathrm{II}$, there are still some context specific issues. For example, looking into the Gulf countries, their approach to urban planning has been highly influenced by Western planning methods which didn't enforce user friendly spaces; but rather planning that is based on one mode for mobility (cars). Through the years, public spaces in the Arab Region like the rest of the world were affected by the push of the planners and authorities for land for housing and other land uses rather than allocating land to open spaces.

The Arab Region's institutional structure has long been debated. The challenges facing the governing systems and the planning regulations have been thoroughly analysed in literature. Most of the countries face similar issues of rapid urbanization, the imbalance between supply and demand of housing, land budgeting and urban planning regulations that leaves little land for public spaces in order to accommodate the rapid urbanization, the mis-location and pricing of housing which partially contributes to informal settlements, land prices speculation and internal migrations to cities. A full loop of issues and challenges that require more than just regulations to fix it but rather a paradigm change in how cities are managed. Topping this with the fact that the centralised financial instruments placed within the governments still struggle to maintain the expenses and burdens of providing basic urban services to a rapidly increasing population.

Since 20II, and after the Arab Spring, public spaces have gained an important position in the Region. The events within the region have given public spaces a politicized stance. Furthermore, international agencies acknowledged that public spaces play vital roles to the community. Public Spaces in cities enhance social cohesion, improves quality of life and is a first step towards civic and economic empowerment. It opens opportunities for greater institutional and political engagement. Public space contributes to well maintained, healthy and safe urban environments, making the city an attractive place to 
live and work for everyone. Also, moving away from main cities, peri urban and rural areas have different sets of community dynamics and are governed by different sets of norms and traditions and might often not have public spaces in the traditional sense. In peri urban and rural areas, communities do establish "public" spaces that they collectively used for celebrations and major spiritual events or markets. The lands allocated for public use are usually donated from the community or the owners are substituted with other lands within the city/village. These issues forcefully place pressures on the government to prioritize a certain set of issues over matters relating to public spaces.

Moreover, these issues are being resolved by relatively outdated laws and mechanisms in planning. Coupled with this, the lack of clear governance systems and slow response to pressing urban issues and most recently the global challenges that pressures countries to swiftly act and push laws and regulations to combat global issues like climate change, economic crises and lately the global pandemic COVID I9.

\section{Public Spaces in the Arab Region}

Public Spaces are a non-commodified urban common, free to use by the different communities. Urban commons typologies' have been blurred with time hindering the ability of communities to take advantage of them and utilize them for the betterment of their lives. Public spaces have several typologies that not everyone is aware of. Public spaces are open spaces like the beaches, waterfronts, avenues, markets, sidewalks, parks, libraries and civic centres. Most countries in the region invest in libraries, civic centres, public markets (esp. those with significant heritage or cultural value). Most of the countries in the Region are more receptive to investing in public spaces yet financing remains an issue. UN-Habitat has worked with different countries around the Region to rehabilitate public spaces; mitigating social and spatial issues and advising on the needed interventions to enhance the public realm.

Throughout the years and with the increase of the influence of privatization and the changes within the urban development regulations in the Region, communities grew and morphed and became more reliant on the term of "private public spaces" as means to enforce power over the space, and deny the right of citizens to use public spaces; while generally, others like stores within downtown central districts have used public spaces as their own property and have expanded their businesses, limiting the usage of public space to other community members. This resulted in spatial and socio-economic inequalities that established itself in the mindset of the communities. Furthermore, the Arab Region still faces other challenges beyond privatization like lack of accessibility to basic urban services which can be noticed in impoverished areas and private gated communities alike due to the rapid urbanization in the Region. The Region also struggles with poor financial managements, violence against women and girls, outdated planning regulations, lack of data on urban topics like informal settlements expansions, ill consideration of women rights, etc. These issues combined with the lack of enforcement of laws limiting such informal extensions and expansions on public spaces, the lack of safety for women, youth and the elderly in public space and the inefficient use of spaces or maintenance has all allowed for public spaces in the Arab Region to be frowned upon and contributed to the expansion and popularity of creating private spaces that is exclusive for certain members of the communities like private sporting 
clubs, gated communities, privatized beaches, etc. These issues influenced local and national authorities' view of public spaces and the method in which they plan for Public Spaces. However, as their role dictates implementing upgrading projects in impoverished areas, public spaces would be rehabilitated in terms of repaving streets, and the sidewalks, greening the streets, and rehabilitating open spaces which in many cases remains closed or operates at a time where people are at work and won't benefit from it.

However, small silo-ed interventions remain an issue for urban development. Urban development agencies are becoming more inclined towards implementing multi-sectoral projects that can be replicated and upscaled and influence national strategies and policies. Part of what public spaces offer to such an approach is its adaptability to include different intersectoral solutions for the community through the different tools and approaches like city wide public space assessments, MineCraft, Kobo toolbox, etc.

\section{UN-Habitat's work in the Arab Region}

UN-Habitat's work in the Arab Region has been aiming towards rehabilitating public spaces that can influence the national urban policies. In order to achieve this, the Global and Regional Public Space programme have implemented pilot projects to demonstrate and prove the ability of public spaces to be a common ground for communities, provide climatic solutions and enhance the socio-economic states of neighbourhoods making them more viable and liveable and moving away from the negative politicized connotations. Countries within the Region are recognizing the importance of having a city-wide plan for public spaces. This has led them to plan to conduct city wide assessments with the aim of rectifying the state of public spaces in their respective countries. Having a city-wide assessment provides governments with a guideline and a base for developing strategic plans for public spaces rehabilitation within the city. City wide assessment looks into the accessibility of public spaces, quantity and its distribution to provide a benchmark against which improvements can be measured. This particularly is important in meeting local targets, and monitoring the implementation of SDG II.7, existing network to identify enablers and barriers for connectivity and linkages, usage, comfort and safety amongst other things. The process of developing such an assessment is flexible enough to take into consideration context specific issues and challenges; leading to develop comprehensive and implementable city-wide public space strategies and policies.

UN-Habitat approaches such projects, assessments and public space inventories using participatory tools. For the city-wide assessment, UN-Habitat employs Kobotool box while also using MineCraft for public space designs. Kobo toolbox is a digital tool that is based on structured questionnaire that can be modified to fit any context as well as assess the priorities for any city. Based on the questionnaire and the needs of the city, the output of such tool is a GIS map that highlights the quality of spaces, its provision, ownership, etc and other factors that the stakeholders deem important and needs to be taken into consideration.

Currently, public spaces have been the focus on many of the countries in the Region given the versatility it has shown with the rise of the pandemic. Public spaces regained its importance as a key component for the citizen's safety and wellbeing. With the lockdown, public spaces provided the community with much needed space for 
destressing emotionally. Although this was highly recognised, some issues with public spaces remain un-tackled and in particular safety for women and girls. Many countries embarked on adding WASH kits for the impoverished communities within these common public spaces. UN-Habitat across the Region supported the local authorities in mitigating the effects of the pandemic and implemented projects that rehabilitated much needed spaces while providing them with water and sanitation connections.

In Palestine and in cooperation with its national and international counterparts, UNHabitat have intervened in Bethlehem to support the users of Public Spaces in being more aware of their personal health, safety and hygiene. Bethlehem is one of the touristic areas in Palestine. The project also aims to provide informative instructions on how to use public spaces and public transportation in order to reduce the chance of getting infected. UN-Habitat also disinfected and sterilized 19 crowded/ main public spaces and solid waste management collection points in Bethlehem. The spaces selection was based on the needs and priorities presented by the local authorities. Moreover, the project installed physical sanitation and hygiene units (while taking into consideration the safety measures on minimal contact). The selection of the locations was based on the findings of the audit surveys conducted by UN-Habitat.

\section{Case Studies}

Looking into Egypt, the government has been preserving significant architectural and urban elements. The city has witnessed several political and socio-economic changes. This could be clearly seen throughout Cairo in different neighbourhoods but most significantly in Cairo's central business district (Downtown Cairo).

The neighbourhood represents all the political and socio-economic changes that the country has gone through. It hosts valuable historic urban and architectural units. It is important to point out that when the neighbourhood was designed (following Hausmann's approach), it was intended to have several public spaces and villas; aiming at hosting the royal family (Abdeen Presidential palace that is now Cairo's government headquarters) and most affluent families. Moreover, the district is architecturally rich with buildings from different international architects and different styles. Given its importance, there have been several actions taken by the government to rehabilitate the neighbourhood. UN-Habitat with the assistance of the government, have developed a strategic plan to revitalise the neighbourhood with focus on rehabilitating public spaces; by conducting a neighbourhood-wide public space assessment. The assessment took into consideration the quality, connectivity, and importance of the different public spaces in alignment with the strategic plan for the district. UN-Habitat formed a strategy with an objective of "creating and enhancing a legible public space and movement network that connects the main public spaces, destinations and landmarks; and to create a network of new green space and open spaces". UN-Habitat then, rehabilitated one of the public spaces- Abdeen square. The plaza or square lies in front of Abdeen Palace -the royal palace- that once hosted the Khedieve. The rehabilitation transformed the square from a parking lot to an inclusive, accessible and green public space. The design of Abdeen Square also ensured the adaptation of measures supportive of walking and cycling, and landscape elements to ensure safety for all ages (pathways circulation - ground-cover transitions and lighting. 
In Tunisia, in cooperation with the municipality of Midoun in Djerba Island and through a NGO (Tunaruz), UN-Habitat have rehabilitated a public space in an impoverished area called Oulad Omar. The public space existed within a residential area and was being used for illicit behaviour. UN-Habitat and the NGO engaged the different community members in a participatory design workshop using MineCraft. The workshop brought women, youth, children and the elderly together where they worked together in mixed groups on designing the space. MineCraft played a crucial role as a tool for participatory design. It allowed the community to visualize their needs through designing within the space in 3D, which allows for realistic designs that are later consolidated into a main design that takes into consideration the main common elements of the design between the groups.

\section{The way forward}

There is much to be done in the Region in planning for public spaces and allocating more land and resources, collecting data on the different interactions within public spaces (eg: violence against women and girls, expansion of public spaces and their changes, quality, etc) capacitating local and national authorities on competing with international organizations for funding from donors on issues related to public spaces and on developing participatory project implementation and for strategically developing public space networks, in developing maintenance strategies and on other city management related matters. Moreover, governance structures can still be further adopted to include stronger representation from the civil community and stronger ownership from the community. Needless to say, those rural areas are still understudied and still under-represented.

Currently, UN-Habitat is building on its past vast and diverse experiences to tackle the issues surrounding public spaces in the Region. It is currently focusing on three vulnerable groups; women, girls and children through developing sub-programmes that concentrate on creating safe public spaces for these groups. These sub-programmes would address the challenges that are facing the region in terms of design, capacity development and knowledge sharing with focus on the women, girls and children safety. Using UN-Habitat's experience and the lesson learnt from the projects, the subprogrammes would fill in the regional gaps and to implement more strategic projects that can influence the national policies and that can guide local and national authorities in developing city-wide development plans for public spaces and guidelines for city- wide assessments.

For child friendly public spaces, UN-Habitat, UNICEF and WHO are jointly supporting the development of Global Principles and Guidance for "Public Spaces for Children" to support national and subnational authorities and stakeholders to accelerate achievement of target II.7 of the 2030 Agenda. For women and girls, the programme will look into the public spaces designs and policies that govern them with a focus on how to support women through designing public spaces that empower women and allow them to enjoy the public life without fear. These sub-programmes will utilise participatory tools to ensure ownership from the stakeholders. 